\title{
BIBECHANA
}

A Multidisciplinary Journal of Science, Technology and Mathematics

ISSN 2091-0762 (Print), 2382-5340 (0nline)

Journal homepage: http://nepjol.info/index.php/BIBECHANA

Publisher: Research Council of Science and Technology, Biratnagar, Nepal

\section{Theoretical investigations on temperature dependence of thermodynamic properties and concentration fluctuations of In-Tl binary liquid alloys by optimization method}

\author{
G. K. Shrestha ${ }^{1,2, *}$ B. K. Singh ${ }^{1}$, I. S. Jha ${ }^{3}$ \\ ${ }^{1}$ University Department of Physics, T.M. Bhagalpur University, Bhagalpur, India. \\ ${ }^{2}$ Pulchowk Campus, IOE, Lalitpur, Tribhuvan University, Nepal. \\ ${ }^{3}$ M.M.A.M. Campus, Biratnagar, Tribhuvan University, Nepal. \\ *Email: ganeshphy50@gmail.com \\ Article history: Received 01 October, 2017; Accepted 21 October, 2017 \\ DOI: http://dx.doi.org/10.3126/bibechana.v15i0.18470
}

This work is licensed under the Creative Commons CC BY-NC License.

https://creativecommons.org/licenses/by-nc/4.0/

\section{(c) (i) (8)}

Abstract

The thermodynamic properties, i.e. free energy of mixing $\left(\mathrm{G}_{M}\right)$, heat of mixing $\left(\mathrm{H}_{M}\right)$, entropy of mixing $\left(\mathrm{S}_{\mathrm{M}}\right)$ and activity $\left(\mathrm{a}_{\mathrm{i}}\right)$ of the component $\mathrm{i}(\mathrm{i} \equiv \mathrm{In} ; \mathrm{Tl})$, and structural property i.e. concentration fluctuations in long wave-length limit $\left[\mathrm{S}_{\mathrm{cc}}(0)\right]$ of $\mathrm{In}-\mathrm{Tl}$ binary liquid alloy at a specified temperature have been investigated in the framework of quasi-lattice model on assuming the coupled effect of size ratio and entropic (or energetic) as well as enthalpic effect. These properties of In-Tl liquid alloy at $723 \mathrm{~K}$ have been computed theoretically by estimating the best fit value of order energy parameter (W) and size ratio $(\Omega)$ over the entire range of concentration in order to match their experimental values. The best fit value of $\mathrm{W}$ at $723 \mathrm{~K}$ has been used to determine the values of $\mathrm{W}$ at different temperatures with the help of temperature derivative of $\mathrm{W}$ which are then used for the optimization procedure in order to calculate the corresponding values of excess free energy of mixing, partial excess free energy of mixing and activity of the components involved in the alloy at different temperatures. These parameters have been used to investigate the concentration fluctuations in long wavelength limit $\{\operatorname{Scc}(0)\}$ of In-Tl binary liquid alloy at different temperatures over the entire range of concentration which have been used to predict the various other structural properties like excess stability function $\left(\mathrm{E}^{\mathrm{XS}}\right)$, diffusion coefficient ratio $\left(\mathrm{D}_{\mathrm{m}} / \mathrm{D}_{\mathrm{id}}\right)$, short range order parameter $\left(\alpha_{1}\right)$ at different temperatures.

Keywords: Order energy parameter; Concentration fluctuations; Free energy of mixing; Optimization procedure.

\section{Introduction}

A binary alloy is a mixture of two elemental metals. In present days, various binary alloys have wide applications in many industries than their component element because of dramatic improvement in various useful properties like hardness, corrosion resistance, wear resistance, mechanical strength, fatigue strength, etc. As regards mixing of two metals, it is widely known that most metals dissolve in one another readily once they are in liquid phase but the same is not true for solid alloys. The 
solubility of homogeneous solid phase is governed by size mismatch, electro-negativity difference and electron concentrations (i.e. electron per atom ratio). Experience shows that these factors cannot be used effectively to interpret the alloying behaviour of liquid alloys to a great deal. The characteristic behaviour may be regarded as to the coupled effect of the energetic and structural arrangement of the constituent elemental metals. From the metallurgical standpoint, they are very important because many binary solid alloys are formed by cooling from a liquid phase. It is suggested that the energetic of the formation of solid alloys can be understood by the knowledge of the corresponding liquid phase. From the theory of liquid state, the liquid alloys are supposed to be simple liquids where structure is usually determined by two body central interactions.

The liquid alloys are considered as disordered systems because they do not have long range order or magnetic order in them. The physical properties like thermodynamic, structural, surface, transport, electrical, etc. of liquid alloys show interesting behaviour as a function of concentration. Thus the mixing behaviour of liquid alloys generates manifold interest for physicists, chemists and metallurgists. The anomaly in the properties of mixing of liquid alloys is least understood. Hence, extensive theoretical investigations are required for the study of the mixing properties of binary liquid alloys. Since long, the theoreticians have been working on various models [1-22] to interpret the physical properties of liquid alloys matching with available experimental results so that the mixing behaviour could adequately be understood.

In the present research work, we have applied quasi-lattice model on assuming the coupled effect of size ratio and energetic (or enthalpic) contribution along with entropic effect to derive the analytical expressions for the thermodynamic properties like free energy of mixing $\left(\mathrm{G}_{\mathrm{M}}\right)$, activity $\left(\mathrm{a}_{\mathrm{i}}\right)$, entropy of mixing $\left(\mathrm{S}_{\mathrm{M}}\right)$, heat of mixing $\left(\mathrm{H}_{\mathrm{M}}\right)$ and concentration fluctuations in long wavelength limit $\left(\mathrm{S}_{\mathrm{cc}}(0)\right)$ of In-Tl binary liquid alloys as discussed in section-2. The analytical expression for free energy of mixing $\left(\mathrm{G}_{\mathrm{M}}\right)$ contains two input parameters i.e. the size ratio $(\Omega)$ and order energy parameter $(\mathrm{W})$. The input parameters $\mathrm{W}$ and $\Omega$ have been estimated by the method of successive approximation on using the experimental values of $\mathrm{G}_{\mathrm{M}}$ of $\mathrm{In}-\mathrm{Tl}$ binary liquid alloys at $723 \mathrm{~K}$ and temperature derivative of $\mathrm{W}$ i.e. $\frac{\partial \mathrm{W}}{\partial \mathrm{T}}$ has been estimated by the same process on using the experimental values of $\mathrm{S}_{\mathrm{M}}$ of In-Tl binary liquid alloys at $723 \mathrm{~K}$. The computed values of free energy of mixing $\left(\mathrm{G}_{\mathrm{M}}\right)$, activity (ai), entropy of mixing $\left(\mathrm{S}_{\mathrm{M}}\right)$, heat of mixing $\left(\mathrm{H}_{\mathrm{M}}\right)$ and concentration fluctuations in long wavelength limit $\left(\mathrm{S}_{\mathrm{cc}}(0)\right)$ of In-Tl binary liquid alloys at $723 \mathrm{~K}$ are compared with the corresponding experimental values in all the concentration ranging from 0.1 to 0.9 in section- 3 .

Further, the temperature dependence of the concentration fluctuations in the long wavelength limit, $\mathrm{S}_{\mathrm{cc}}(0)$ of In-Tl binary liquid alloy has been computed by the optimization procedure [23] on taking into account of the thermodynamic data, theoretically obtained. The optimized coefficients set of excess free energy of mixing $\left(G_{M}^{X S}\right)$ have been used to compute partial excess free energy of mixing of each component $\left(\breve{G}_{M, i}^{X S}\right)$, excess free energy of mixing $\left(G_{M}^{X S}\right)$, activity $\left(a_{i}\right)$ of the component $i(i \equiv$ $\mathrm{In} ; \mathrm{Tl}$ ), and concentration fluctuations in long wavelength limit, $\mathrm{S}_{\mathrm{cc}}(0)$ in the entire range of concentration for the In-Tl binary liquid alloy at four different temperatures i.e. $723 \mathrm{~K}, 1123 \mathrm{~K}, 1223$ $\mathrm{K}$ and $1323 \mathrm{~K}$ in section-4. These values of concentration fluctuations in long wavelength limit $\left(\mathrm{S}_{\mathrm{cc}}(0)\right)$ of In-Tl binary liquid alloy at above mentoined temperatures as a function of concentration have been used to determine the various other structural properties like excess stability function $\left(\mathrm{E}^{\mathrm{XS}}\right)$, diffusion coefficient ratio $\left(D_{m} / D_{\text {id }}\right)$, short range order parameter $\left(\alpha_{1}\right)$ at corresponding temperatures.

\section{Formalism}

Let us assume one mole binary liquid mixture of constituent $\mathrm{X}(\equiv \mathrm{In})$ and constituent $\mathrm{Y}(\equiv \mathrm{Tl})$ in which the constituent atoms $\mathrm{X}$ and $\mathrm{Y}$ of the binary mixture are different in shape and size from each other. We consider the constituent $\mathrm{X}$ has concentration $\mathrm{c}_{\mathrm{X}}=\mathrm{c}$ and the constituent $\mathrm{Y}$ has concentration $c_{Y}=(1-c)$ so that $c_{N}=N_{X}$ (No. of constituent $X$ ) and (1-c) $N=N_{Y}$ (No. of constituent $Y$ ) where $N$ represents Avogadro's Number. As explained by Guggenheim [24] in the limit Z (the coordination number) $\rightarrow \infty$ on considering the coupled effect of size ratio and entropic (or energetic) as well as 
enthalpic effect of the binary mixture (so that $\mathrm{H}_{\mathrm{M}} \neq 0$ ), the Quasi- Lattice Theory (QLT) of liquid mixture gives an expression for free energy of mixing $\left(\mathrm{G}_{\mathrm{M}}\right)$ at a temperature $(\mathrm{T})$ which is represented by

$$
G_{M}=R T[(1-c) \ln \psi+c \ln (1-\psi)+c \psi W]
$$

where the first two terms on right hand side appear due to entropic contribution and last term appears due to enthalpic contribution.

Here, $\mathrm{R}$ is the molar gas constant,

And $\psi=\frac{\Omega(1-c)}{c+\Omega(1-c)}$

where $\Omega\left(=\frac{\Omega_{Y}}{\Omega_{X}} ; \Omega_{Y}>\Omega_{X}\right)$ is the size ratio of the alloy.

Also, $\mathrm{W}=\gamma_{\mathrm{X}}\left(\frac{\omega}{\mathrm{K}_{\mathrm{B}} \mathrm{T}}\right)$

which represents order energy parameter

Here, $\gamma_{X}$ is the number of a group of lattice sites, occupying by $N_{X}$ atoms of the constituent $X, K_{B}$ is the Boltzmann constant and $\omega$ is the interchange energy, given by

$$
\omega=\left(\epsilon_{X Y}-\frac{\epsilon_{X X}+\epsilon_{Y Y}}{2}\right)
$$

where $\epsilon_{\mathrm{ij}}(\mathrm{i} ; \mathrm{j} \equiv \mathrm{In} ; \mathrm{Tl})$ is $\mathrm{i}-\mathrm{j}$ bond strength.

\subsection{Activity $\left(a_{i}\right)$ of constituent $i$}

From the standard thermodynamic relation, the activity of a constituent $i$ of the binary liquid alloy, is given by

$$
R T \ln a_{i}=G_{M}+c_{j}\left(\frac{\partial G_{M}}{\partial c_{i}}\right)
$$

where $a_{i}$ and $c_{j}$ are the activity and concentration of component $i$ and $j(i ; j \equiv I n ; T l)$ respectively.

On solving equation (5) by using equation (1), we obtain

Also,

$$
\ln a_{X}=\ln (1-\psi)+\psi\left\{\frac{(\Omega-1)}{\Omega}\right\}+\psi^{2} W
$$

$$
\ln a_{Y}=\ln \psi-(1-\psi)(\Omega-1)+W \Omega(1-\psi)^{2}
$$

where $\mathrm{a}_{\mathrm{X}}$ and $\mathrm{a}_{\mathrm{Y}}$ are the activities of the constituent $\mathrm{X}$ and $\mathrm{Y}$ respectively.

\subsection{Concentration Fluctuations in Long Wave-length Limit $(\operatorname{Scc}(0))$}

As explained by Bhatia and Thornton [25], the concentration fluctuations in long wavelength limit $\left\{\mathrm{S}_{\mathrm{c}}(0)\right\}$ of binary liquid alloy at a temperature $(\mathrm{T})$ is given by

$$
S_{c c}(0)=\frac{R T}{\left(\frac{\partial^{2} \mathrm{G} M}{\partial \mathrm{c}^{2}}\right)_{\mathrm{P}, \mathrm{N}, \mathrm{T}}}
$$

On solving equation (8) by using equation (1), we obtain

$$
S_{c c}(0)=\frac{c(1-c)}{1-c(1-c)\{f(\Omega, W)\}}
$$

with $f(\Omega, W)=\frac{2 \Omega^{2} W-(\Omega-1)^{2}\{c+\Omega(1-c)\}}{\{c+\Omega(1-c)\}^{3}}$

In the other hand, the experimental value of concentration fluctuations in long wavelength limit can also be determined from the activity (which is measured directly in experiment) as explained by Singh [26] on using the relation

$$
S_{c c}(0)=\mathrm{c}_{\mathrm{i}} \mathrm{a}_{\mathrm{j}}\left(\frac{\partial \mathrm{a}_{\mathrm{j}}}{\partial \mathrm{c}_{\mathrm{j}}}\right)_{\mathrm{T}, \mathrm{P}}^{-1}
$$

where $c_{i}$ and $a_{j}$ are the concentration and activity of component $i$ and $j(i ; j \equiv I n$; $T l$ ) respectively.

Also, the ideal value of concentration fluctuations is obtained from the relation

$$
s_{c c}^{i d}(0)=c(1-\mathrm{c})
$$

The concentration fluctuations in long wavelength limit $\left(S_{c c}(0)\right)$ is the structural property of binary liquid alloys which gives the idea to understand the nature of liquid alloys. The mixing behaviour, i.e. 
the nature of interaction of constituent atoms of binary liquid alloys can be analyzed with the help of deviation of $S_{c c}(0)$ from $s_{c c}^{i d}(0)$. For the given composition, the binary liquid alloys is of ordering nature, if $S_{c c}(0)<s_{c c}^{i d}(0)$, but segregating nature, if $S_{c c}(0)>s_{c c}^{i d}(0)$. Further, various properties of binary liquid alloys like excess stability function $\left(\mathrm{E}^{\mathrm{XS}}\right)$, diffusion coefficient ratio $\left(\mathrm{D}_{\mathrm{m}} / \mathrm{D}_{\mathrm{id}}\right)$, short range order parameter $\left(\alpha_{1}\right)$ can be computed by using the concept of concentration fluctuations in long wavelength limit.

\subsection{Entropy of Mixing $\left(S_{M}\right)$}

From the standard thermodynamic relation, the Entropy of mixing for a binary liquid alloys is given by

$$
S_{M}=-\frac{\partial\left(G_{M}\right)}{\partial T}
$$

On solving this equation by using equation (1), we obtain

$$
\frac{S_{M}}{R}=-\left[(1-c) \ln \psi+c \ln (1-\psi)+c \psi\left(W+T \frac{\partial W}{\partial T}\right)\right]
$$

\subsection{Heat of Mixing $\left(\mathrm{H}_{\mathrm{M}}\right)$}

From the standard thermodynamic relation, the heat of mixing for a binary liquid alloys is given by

$$
\frac{H_{M}}{R T}=\frac{G_{M}}{R T}+\frac{S_{M}}{R}=-c \psi T\left(\frac{\partial W}{\partial T}\right)
$$

\section{Results and Discussion}

The free energy of mixing $\left(\mathrm{G}_{\mathrm{M}}\right)$ and activity $\left(\mathrm{a}_{\mathrm{i}}\right)$ of the constituent $\mathrm{i}(\mathrm{i} \equiv \mathrm{In}$; Tl ) of binary liquid alloys at a specified temperature have two input parameters i.e. size ratio $(\Omega)$ and order energy parameter (W) so that they are needed to compute them. The size ratio $(\Omega)$ for a binary liquid alloy has been estimated by knowing the atomic volumes of the constituent $i$ at the specified temperature, $\mathrm{T}$ from the relation

$$
\Omega_{i(T)}=\Omega_{i\left(T_{m}\right)}\left[1+\alpha_{p i}\left(T-T_{m}\right)\right]
$$

where $\Omega_{i\left(T_{m}\right)}$ is the atomic volume of the constituent $\mathrm{i}$ at the melting temperature ( $\left.\mathrm{T}_{\mathrm{m}}\right)$ and $\alpha_{p i}$ is the coefficient of thermal expansion of the constituent $i$.

On taking the values of $\alpha_{\mathrm{pi}}$ and $\Omega_{i\left(T_{m}\right)}$ for In and Tl from Shimoji [27], the value of size ratio $(\Omega)$ for In-Tl binary liquid alloy at $723 \mathrm{~K}$ is found to be 1.0973 . However, this value of size ratio $(\Omega)$ and order energy parameter (W) for In-Tl binary liquid alloy at $723 \mathrm{~K}$ have been adjusted to obtain the theoretical values for thermodynamic properties and concentration fluctuations of In-Tl binary liquid alloys at $723 \mathrm{~K}$ in the entire concentration range, matching with their corresponding experimental values. The values of size ratio $(\Omega)$ and order energy parameter (W) have been estimated from equation (1), (6), (7), and (9) to reproduce simultaneously an overall fit for the experimental values of free energy of mixing $\left(\mathrm{G}_{\mathrm{M}}\right)$, activity $\left(\mathrm{a}_{\mathrm{i}}\right)$ of the component $\mathrm{i}(\mathrm{i}=\equiv \mathrm{In} ; \mathrm{Tl})$ and concentration fluctuations in long wavelength limit $\left\{\mathrm{S}_{\mathrm{cc}}(0)\right\}$ of In-Tl liquid alloys at $723 \mathrm{~K}$ as obtained from Hultgren et. al. [28] in the entire concentration ranging from 0.1 to 0.9 .

In this process, we have determined the best fit value of size ratio $(\Omega)$ and order energy parameter $(\mathrm{W})$ for In-Tl binary liquid alloys at $723 \mathrm{~K}$, which are found to be 1.15 and 0.48 respectively. The theoretical values of $\mathrm{G}_{\mathrm{M}} / \mathrm{RT}$ on taking the values of $\Omega=1.15$ and $\mathrm{W}=0.48$, as computed by using equation (1) and experimental values of $\mathrm{G}_{\mathrm{M}} / \mathrm{RT}$ of In-Tl liquid alloys at $723 \mathrm{~K}$ in the entire concentration ranging from 0.1 to 0.9 [28] are shown in Fig-1, which are in excellent agreement. The theoretical value of $\mathrm{G}_{\mathrm{M}} / \mathrm{RT}$ at $723 \mathrm{~K}$ is minimum at the concentration, $\mathrm{c}=0.5$, which is found to be 0.567125 and the experimental value of $\mathrm{G}_{\mathrm{M}} / \mathrm{RT}$ at $723 \mathrm{~K}$ is minimum at the same concentration, $\mathrm{c}=$ 0.5 which is found to be -0.566600 . 
The theoretical values of $\ln a_{i}$ ( $\mathrm{i} \equiv \mathrm{In} ; \mathrm{Tl}$ ) as computed by using equation (6) and (7) (on taking $\Omega=$ 1.15 and $\mathrm{W}=0.48)$, and experimental values of $\ln a_{i}(\mathrm{i}=\mathrm{X} ; \mathrm{Y})$ of In-Tl liquid alloys at $723 \mathrm{~K}$ [28] in the entire concentration range are shown in Fig-2, which are in excellent agreement.
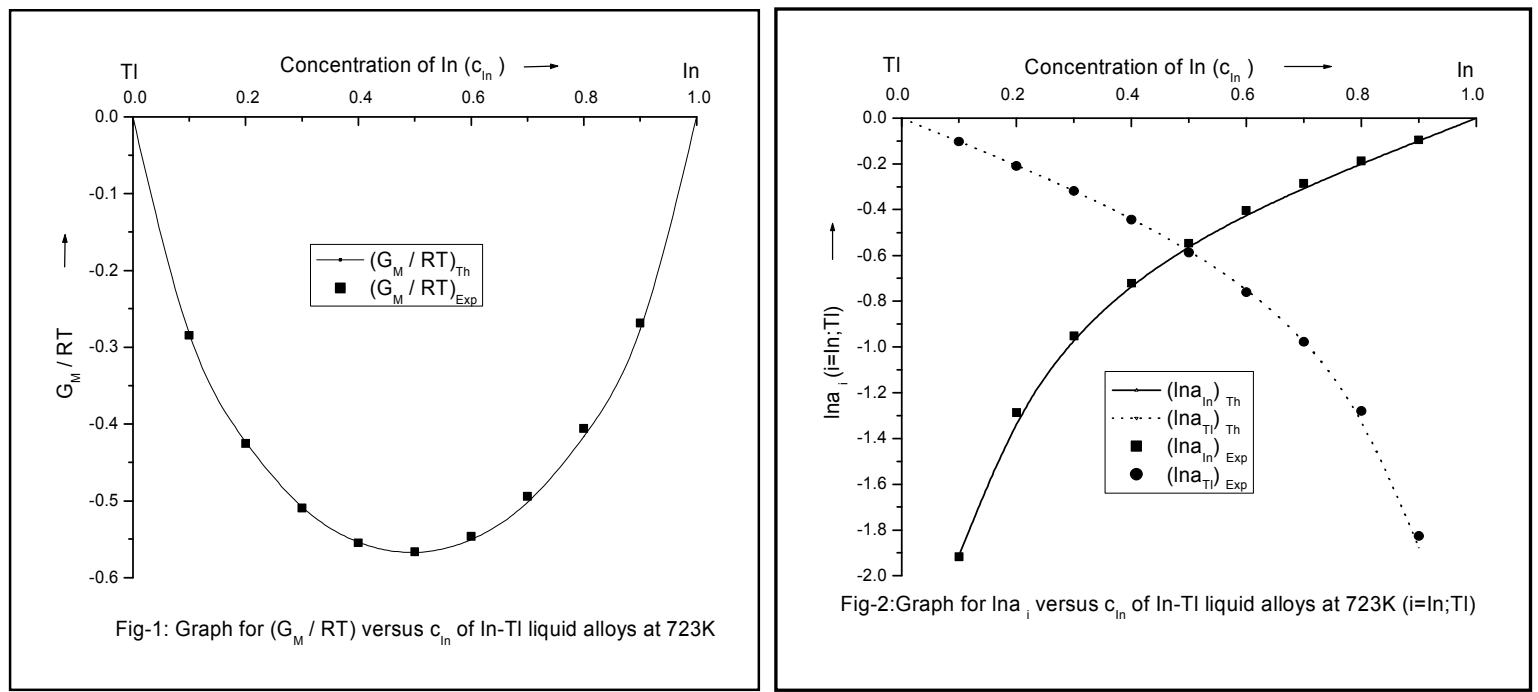

The theoretical values of $S_{c c}(0)$ for In-Tl binary liquid alloys at $723 \mathrm{~K}$ in the entire concentration range have been calculated by using the equation (9) (on taking $\Omega=1.15$ and $\mathrm{W}=0.48$ ) while the experimental values of concentration fluctuations in long wave-length limit $\left(S_{c c}(0)\right)$ have been calculated by using the experimental values of activity in equation (11). The theoretical and experimental values of $S_{c c}(0)$ in In-Tl liquid alloys at $723 \mathrm{~K}$ in the entire concentration range are shown in Fig-3, which are in reasonable agreement with some discrepancies in the concentration range $0.4<c_{I n}<0.7$. The theoretical value of $S_{c c}(0)$ is maximum at the concentration, $\mathrm{c}=0.5$ which is found to be 0.333612 while the experimental value of $S_{c c}(0)$ is maximum at the same concentration, $\mathrm{c}=0.5$ which is found to be 0.318222 . It is obvious that the concentration fluctuations in long wavelength limit $\left\{S_{c c}(0)\right\}$ of In-Tl liquid alloy at $723 \mathrm{~K}$ is greater than the ideal value of concentration fluctuations $\left\{S_{c c}^{i d}(0)\right\}$ at each concentration which confirms that the In-Tl liquid alloy has segregating nature.

The value of temperature derivative of order energy parameter, i.e. $\frac{\partial W}{\partial T}$, for In-Tl binary liquid alloy has been estimated from equation (13) or (14) to reproduce simultaneously an overall fit for the experimental values of entropy of mixing $\left(\mathrm{S}_{\mathrm{M}}\right)$ or heat of mixing $\left(\mathrm{H}_{\mathrm{M}}\right)$ of In-Tl liquid alloy at $723 \mathrm{~K}$ in the entire concentration ranging from 0.1 to 0.9 . The best fit value of $\frac{\partial W}{\partial T}$ for In-Tl liquid alloy is found to be $-0.00048 \mathrm{~K}^{-1}$. The theoretical values of $\mathrm{S}_{\mathrm{M}} / \mathrm{R}$ as computed by using equation (13) and the corresponding experimental values of $\mathrm{In}-\mathrm{Tl}$ liquid alloys at $723 \mathrm{~K}$ in the entire concentration range are shown in Fig-4, which are in excellent agreement. The theoretical value of $S_{M} / R$ at $723 \mathrm{~K}$ is maximum at the concentration, $c=0.5$ which is found to be 0.660028 while the experimental value of $S_{M} / R$ at $723 \mathrm{~K}$ is maximum at the same concentration, $\mathrm{c}=0.5$, which is found to be 0.659200 .

Again, the theoretical values of $\mathrm{H}_{\mathrm{M}} / \mathrm{RT}$ (on taking $\frac{\partial W}{\partial T}=-0.00048 \mathrm{~K}^{-1}$ ) as computed by using equation (14) and experimental values of $\mathrm{H}_{\mathrm{M}} / \mathrm{RT}$ of In-Tl liquid alloys at $723 \mathrm{~K}$ in the entire concentration range are shown in Fig-5, which are in reasonable agreement. The theoretical value of $\mathrm{H}_{\mathrm{M}} / \mathrm{RT}$ at $723 \mathrm{~K}$ is maximum at the concentration, $\mathrm{c}=0.5$ which is found to be 0.092813 but the experimental value of $\mathrm{H}_{\mathrm{M}} / \mathrm{RT}$ at $723 \mathrm{~K}$ is maximum at the concentration, $\mathrm{c}=0.6$ which is found to be 0.094700 . 

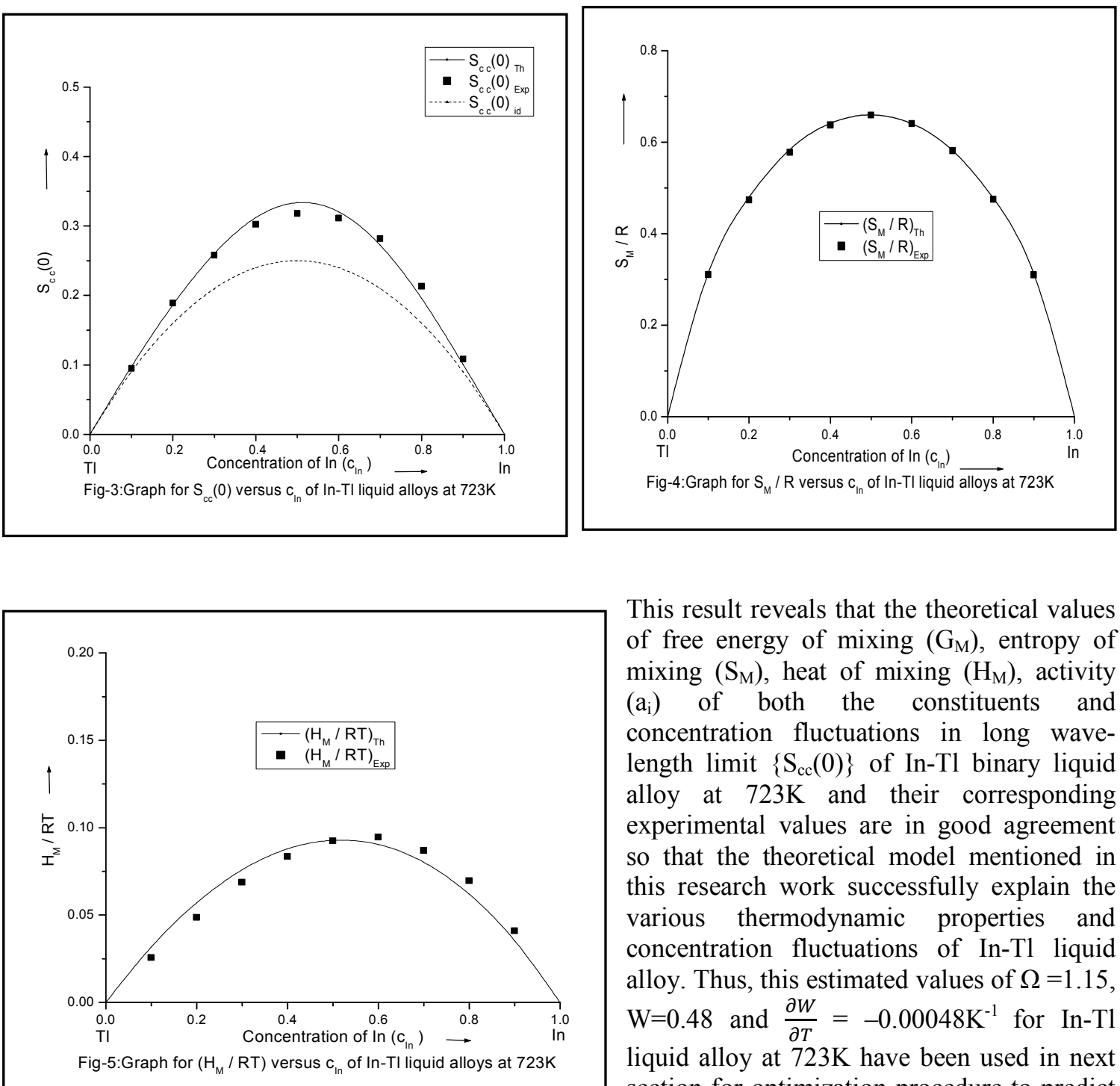

This result reveals that the theoretical values of free energy of mixing $\left(\mathrm{G}_{\mathrm{M}}\right)$, entropy of mixing $\left(\mathrm{S}_{\mathrm{M}}\right)$, heat of mixing $\left(\mathrm{H}_{\mathrm{M}}\right)$, activity $\left(a_{i}\right)$ of both the constituents and concentration fluctuations in long wavelength limit $\left\{\mathrm{S}_{\mathrm{cc}}(0)\right\}$ of $\mathrm{In}-\mathrm{Tl}$ binary liquid alloy at $723 \mathrm{~K}$ and their corresponding experimental values are in good agreement so that the theoretical model mentioned in this research work successfully explain the various thermodynamic properties and concentration fluctuations of In-Tl liquid alloy. Thus, this estimated values of $\Omega=1.15$, $\mathrm{W}=0.48$ and $\frac{\partial W}{\partial T}=-0.00048 \mathrm{~K}^{-1}$ for $\mathrm{In}-\mathrm{Tl}$ liquid alloy at $723 \mathrm{~K}$ have been used in next section for optimization procedure to predict the thermodynamic properties and concentration fluctuations in long wave-length limit of In-Tl liquid alloys at different temperatures.

\section{Optimization of free energy of mixing, activity, concentration fluctuations}

Optimization procedure is the thermodynamic explanation in which statistical thermodynamics and polynomial expressions are used. It has good potential to obtain a consistent set of model parameters analytically which gives the idea to extrapolate into temperature and concentration region in which the direct experimental observation is not available. The adjustable coefficients, used in this process, are estimated by least-square method.

The various thermodynamic properties, described by a power-series law whose coefficients are A, B, $\mathrm{C}, \mathrm{D}, \mathrm{E}, \ldots . .$. (say), are determined by least-square method [23]. The heat capacity at a temperature (T) can be expressed as

$$
C_{p}=-C-2 D T-2 E T^{-2}-
$$

From the thermodynamic relation, the enthalpy is given by

$$
H=H\left(T_{0}\right)+\int_{0}^{\mathrm{T}} \mathrm{C}_{\mathrm{p}} \mathrm{dT}
$$




$$
=A-C T-D T^{2}+2 E T^{-1}-\ldots \ldots \ldots \ldots \ldots
$$

Also, the entropy is given by

$$
\begin{aligned}
S & =S\left(T_{0}\right)+\int_{0}^{\mathrm{T}} \frac{\mathrm{C}_{\mathrm{p}}}{\mathrm{T}} \mathrm{dT} \\
& =-B-C(1+\ln T)-2 D T+E T^{-2}-
\end{aligned}
$$

On using equations (17) and (18), the standard thermodynamic relation, $\mathrm{G}=\mathrm{H}-\mathrm{TS}$, provides the temperature $(\mathrm{T})$ dependent free energy as

$$
G=A+B T+C T \ln T+D T^{2}+E T^{-1}+\ldots \ldots \ldots \ldots .
$$

The concentration dependence of excess free energy of mixing is given by Redlich-Kister polynomial equation as

$$
\begin{aligned}
& G_{M}^{X S}(c, T)=c(1-c) \sum_{l=0}^{m} K_{l}(T)[2 c-1]^{l} \\
& \text { with } K_{l}(T)=A_{l}+B_{l} T+C_{l} T \ln T+D_{l} T^{2}+\ldots \ldots \ldots \ldots
\end{aligned}
$$

The coefficients $K_{l}$ depend upon the temperature like $\mathrm{G}$ in equation (19). The least-square method has been used to obtain the unknown parameters involved in equation (20). So, we need the excess free energy of mixing $\left(G_{M}^{X S}\right)$ of the binary liquid alloys at different temperatures which can be determined by the relation

$$
\begin{aligned}
G_{M}^{X S} & =G_{M}-G_{M}^{i d} \\
& =G_{M}-R T[c \ln c+(1-c) \ln (1-\mathrm{c})]
\end{aligned}
$$

Thus, we require the values of free energy of mixing $\left(\mathrm{G}_{\mathrm{M}}\right)$ of binary liquid alloys at different temperatures which can be computed from equation (1) by knowing the values of order energy parameter $(\mathrm{W})$ at different temperatures from the relation

$$
W\left(T_{k}\right)=W(T)+\frac{\partial W}{\partial T}\left(\mathrm{~T}_{\mathrm{K}}-\mathrm{T}\right)
$$

where $\mathrm{W}(\mathrm{T})$ is the order energy parameter at the given temperature $T, W\left(T_{k}\right)$ is order energy parameter at required temperature $T_{k}$ and $\frac{\partial W}{\partial T}$ represents temperature derivative of order energy parameter for the given liquid alloy. By using the best fit value of $\frac{\partial W}{\partial T}$ and $\mathrm{W}(\mathrm{T})$ at the given temperature $T=723 \mathrm{~K}$ (as obtained in section-3) in equation (23), the values of $\mathrm{W}\left(\mathrm{T}_{\mathrm{k}}\right)$ at temperatures $\mathrm{T}_{\mathrm{k}}=1123 \mathrm{~K}, 1223 \mathrm{~K}, 1323 \mathrm{~K}$ are estimated and listed in Table- 1 .

Table-1: Estimated values of order energy parameter (W) at different temperatures in In-Tl liquid alloys.

\begin{tabular}{|c|c|}
\hline Temperature $\left(\mathrm{T}_{\mathrm{k}}\right)$ in $\mathrm{K}$ & Order Energy Parameter, $\mathrm{W}\left(\mathrm{T}_{\mathrm{k}}\right)$ \\
\hline 723 & 0.480 \\
\hline 1123 & 0.288 \\
\hline 1223 & 0.240 \\
\hline 1323 & 0.192 \\
\hline
\end{tabular}

It is also noted that the change in temperature may change the size ratio $(\Omega)$ of In-Tl liquid alloy but the consequent change in the values of various thermodynamic properties of the alloys is obtained in negligible amount only. Thus, for entire calculation of thermodynamic and other properties, the value of size ratio is taken as constant (i.e. $\Omega=1.15$ for In-Tl liquid alloy at all temperatures). The values of free energy of mixing $\left(\mathrm{G}_{\mathrm{M}}\right)$ of In-Tl liquid alloys at different temperatures (i.e. at $723 \mathrm{~K}, 1123 \mathrm{~K}$, $1223 \mathrm{~K}$ and $1323 \mathrm{~K}$ ) have been calculated by using the corresponding values of $\mathrm{W}$ in equation (1) in the entire range of concentration and then they are used to calculate the corresponding excess free energy of mixing $\left(G_{M}^{X S}\right)$ of In-Tl liquid alloys at different temperatures (i.e. at $723 \mathrm{~K}, 1123 \mathrm{~K}, 1223 \mathrm{~K}$ and $1323 \mathrm{~K}$ ) by using equation (22).

The least-square method has been used to calculate the parameters involved in equation (20) and then the optimized coefficients for In-Tl liquid alloys are computed which are listed in the Table-2. 
G.K. Shrestha et al. / BIBECHANA 15 (2018) 11-23: RCOST p.18

Table-2: Calculated values of optimized coefficients $\mathrm{A}_{l}, \mathrm{~B}_{l}, \mathrm{C}_{l}, \mathrm{D}_{l}(l=0$ to 3$)$ for In-Tl liquid alloy.

\begin{tabular}{|c|l|c|c|c|}
\hline Values of $l$ & $\mathrm{~A}_{l}\left(\mathrm{~J} \mathrm{~mol}^{-1}\right)$ & $\mathrm{B}_{l}\left(\mathrm{~J} \mathrm{~mol}^{-1} \mathrm{~K}^{-1}\right)$ & $\mathrm{C}_{l}\left(\mathrm{~J} \mathrm{~mol}^{-1} \mathrm{~K}^{-1}\right)$ & $\mathrm{D}_{l}\left(\mathrm{Jmol}^{-1} \mathrm{~K}^{-2}\right)$ \\
\hline 0 & -0.0000000034 & 7.2745953781 & 0.0000000000 & -0.0042691409 \\
\hline 1 & -0.0000000010 & 0.5094149143 & 0.0000000000 & -0.0002978470 \\
\hline 2 & 0.0000000025 & 0.0356759527 & 0.0000000000 & -0.0000208206 \\
\hline 3 & -0.0000000047 & 0.0024917775 & 0.0000000000 & -0.0000014526 \\
\hline
\end{tabular}

Further, the optimized value of partial excess free energy of mixing of the constituent $X(\equiv \operatorname{In})$ and $\mathrm{Y}(\equiv \mathrm{Tl})$ in $\mathrm{In}-\mathrm{Tl}$ liquid alloys are respectively given by

and

$$
\tilde{G}_{M, X}^{X S}(c, T)=(1-c)^{2} \sum_{l=0}^{m} K_{l}(T)[2 c(l+1)-1](2 c-1)^{l-1}
$$

$$
\tilde{G}_{M, Y}^{X S}(c, T)=c^{2} \sum_{l=0}^{m} K_{l}(T)[2 c(l+1)-2 l-1](2 c-1)^{l-1}
$$

The partial excess free energy of mixing of both the components In and $\mathrm{Tl}$ of In-Tl liquid alloys at different temperatures (i.e. $723 \mathrm{~K}, 1123 \mathrm{~K}, 1223 \mathrm{~K}$ and $1323 \mathrm{~K}$ ) have been calculated separately over the entire concentration range by equations (24) and (25) with the help of optimized coefficients. These optimized values of partial excess free energy of mixing of both the components involved in the alloy have also been used to obtain the corresponding excess free energy of mixing for In-Tl liquid alloys at different temperatures in the entire concentration range from the relation

$$
G_{M}^{X S}(c, T)=c\left\{\tilde{G}_{M, X}^{X S}(c, T)\right\}+(1-c)\left\{\tilde{G}_{M, Y}^{X S}(c, T)\right\}
$$

The optimized values of excess free energy of mixing for In-Tl liquid alloys at different temperatures, $\mathrm{T}=723 \mathrm{~K}, 1123 \mathrm{~K}, 1223 \mathrm{~K}$ and $1323 \mathrm{~K}$ in the entire concentration range are shown in Fig- 6.

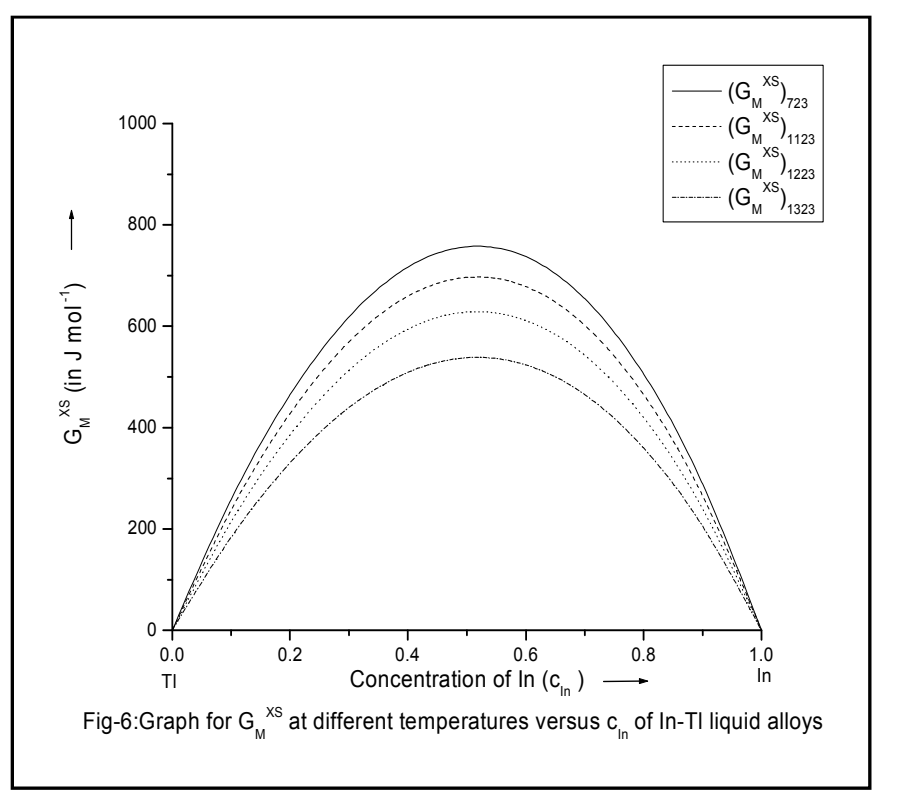

Again, the optimized values of activity coefficients $\left(\gamma_{\mathrm{i}}\right)$ in the entire concentration range of the component $i$, (i $\equiv \mathrm{In} ; \mathrm{Tl}$ ) at corresponding temperature have been computed from the relation

$$
\begin{aligned}
& \tilde{G}_{M, i}^{X S}=R T \ln \gamma_{i} \\
& \text { with } \gamma_{i}=\frac{\mathrm{a}_{\mathrm{i}}}{\mathrm{c}_{\mathrm{i}}}
\end{aligned}
$$

where $a_{i}$ and $c_{i}$ be the activity and concentration of the component $\mathrm{i}$ ( $\mathrm{i} \equiv \mathrm{In}$; $\mathrm{Tl})$ respectively of $\mathrm{In}-\mathrm{Tl}$ liquid alloys at corresponding temperature.

The optimized values of partial excess free energy of mixing, the corresponding activity coefficients and hence activity of both the components involved in In-Tl liquid alloys in the entire concentration range at the temperatures $\mathrm{T}=723 \mathrm{~K}, 1123 \mathrm{~K}, 1223 \mathrm{~K}$ and $1323 \mathrm{~K}$ are noted in Table-3, Table- 4 , Table- 5 and Table- 6 respectively. 
Table-3: Optimized values of partial excess free energy of mixing, activity coefficients and activity of both the components involved in In-Tl liquid alloys at $723 \mathrm{~K}$.

\begin{tabular}{|c|c|c|c|c|c|c|c|c|c|c|}
\hline \multirow{2}{*}{$c_{I n}$} & \multicolumn{9}{|c|}{ In- component } & \multicolumn{5}{c|}{ Tl-component } \\
\cline { 2 - 12 } & $\tilde{G}_{M, I n}^{X S}$ & $\ln \gamma_{I n}=\frac{\tilde{G}_{M, I n}^{X S}}{R T}$ & $\gamma_{I n}$ & $a_{I n}$ & $\ln a_{I n}$ & $\tilde{G}_{M, T l}^{X S}$ & $\ln \gamma_{T l}=\frac{\tilde{G}_{M, T l}^{X S}}{R T}$ & $\gamma_{T l}$ & $a_{T l}$ & $\ln a_{T l}$ \\
\hline 0.1 & 2353.049 & 0.391 & 1.479 & 0.148 & -1.911 & 25.235 & 0.004 & 1.004 & 0.904 & -0.101 \\
\hline 0.2 & 1909.659 & 0.318 & 1.374 & 0.275 & -1.292 & 103.686 & 0.017 & 1.017 & 0.814 & -0.206 \\
\hline 0.3 & 1502.298 & 0.250 & 1.284 & 0.385 & -0.954 & 239.719 & 0.040 & 1.041 & 0.728 & -0.317 \\
\hline 0.4 & 1134.509 & 0.189 & 1.208 & 0.483 & -0.728 & 438.058 & 0.073 & 1.076 & 0.645 & -0.438 \\
\hline 0.5 & 810.136 & 0.135 & 1.144 & 0.572 & -0.558 & 703.829 & 0.117 & 1.124 & 0.562 & -0.576 \\
\hline 0.6 & 533.360 & 0.089 & 1.093 & 0.656 & -0.422 & 1042.594 & 0.173 & 1.189 & 0.476 & -0.743 \\
\hline 0.7 & 308.744 & 0.051 & 1.053 & 0.737 & -0.305 & 1460.397 & 0.243 & 1.275 & 0.383 & -0.961 \\
\hline 0.8 & 141.268 & 0.024 & 1.024 & 0.819 & -0.200 & 1963.800 & 0.327 & 1.386 & 0.277 & -1.283 \\
\hline 0.9 & 36.373 & 0.006 & 1.006 & 0.905 & -0.099 & 2559.925 & 0.426 & 1.531 & 0.153 & -1.877 \\
\hline
\end{tabular}

Table-4: Optimized values of partial excess free energy of mixing, activity coefficients and activity of both the components involved in In-Tl liquid alloys at $1123 \mathrm{~K}$.

\begin{tabular}{|c|c|c|c|c|c|c|c|c|c|c|}
\hline \multirow[t]{2}{*}{$c_{\text {In }}$} & \multicolumn{5}{|c|}{ In- component } & \multicolumn{5}{|c|}{ Tl-component } \\
\hline & $\tilde{G}_{M, I n}^{X S}$ & $\begin{array}{l}\ln \gamma_{I n} \\
=\frac{\widetilde{G}_{M, I n}^{X S}}{R T}\end{array}$ & $\gamma_{I n}$ & $a_{\text {In }}$ & $\ln a_{I n}$ & $\tilde{G}_{M, T l}^{X S}$ & $\ln \gamma_{T l}=\frac{\tilde{G}_{M, T l}^{X S}}{R T}$ & $\gamma_{T l}$ & $a_{T l}$ & $\ln a_{T l}$ \\
\hline 0.1 & 2164.205 & 0.232 & 1.261 & 0.126 & -2.071 & 23.194 & 0.002 & 1.002 & 0.902 & -0.103 \\
\hline 0.2 & 1756.605 & 0.188 & 1.207 & 0.241 & -1.421 & 95.314 & 0.010 & 1.010 & 0.808 & -0.213 \\
\hline 0.3 & 1382.056 & 0.148 & 1.160 & 0.348 & -1.056 & 220.391 & 0.024 & 1.024 & 0.717 & -0.333 \\
\hline 0.4 & 1043.828 & 0.112 & 1.118 & 0.447 & -0.804 & 402.790 & 0.043 & 1.044 & 0.626 & -0.468 \\
\hline 0.5 & 745.471 & 0.080 & 1.083 & 0.542 & -0.613 & 647.246 & 0.069 & 1.072 & 0.536 & -0.624 \\
\hline 0.6 & 490.846 & 0.053 & 1.054 & 0.632 & -0.458 & 958.901 & 0.103 & 1.108 & 0.443 & -0.814 \\
\hline 0.7 & 284.168 & 0.030 & 1.031 & 0.722 & -0.326 & 1343.339 & 0.144 & 1.155 & 0.346 & -1.060 \\
\hline 0.8 & 130.039 & 0.014 & 1.014 & 0.811 & -0.209 & 1806.629 & 0.193 & 1.213 & 0.243 & -1.416 \\
\hline 0.9 & 33.486 & 0.004 & 1.004 & 0.903 & -0.102 & 2355.354 & 0.252 & 1.287 & 0.129 & -2.050 \\
\hline
\end{tabular}

Table-5: Optimized values of partial excess free energy of mixing, activity coefficients and activity of both the components involved in In-Tl liquid alloys at $1223 \mathrm{~K}$.

\begin{tabular}{|c|c|c|c|c|c|c|c|c|c|c|}
\hline \multirow{2}{*}{$c_{I n}$} & \multicolumn{9}{|c|}{ In- component } & \multicolumn{4}{c|}{ Tl-component } \\
\cline { 2 - 11 } & $\tilde{G}_{M, I n}^{X S}$ & $\ln \gamma_{I n}=\frac{\tilde{G}_{M, I n}^{X S}}{R T}$ & $\gamma_{I n}$ & $a_{I n}$ & $\ln a_{I n}$ & $\tilde{G}_{M, T l}^{X S}$ & $\ln \gamma_{T l}=\frac{\tilde{G}_{M, T l}^{X S}}{R T}$ & $\gamma_{T l}$ & $a_{T l}$ & $\ln a_{T l}$ \\
\hline 0.1 & 1951.069 & 0.192 & 1.212 & 0.121 & -2.111 & 20.903 & 0.002 & 1.002 & 0.902 & -0.103 \\
\hline 0.2 & 1583.705 & 0.156 & 1.169 & 0.234 & -1.454 & 85.904 & 0.008 & 1.008 & 0.807 & -0.215 \\
\hline 0.3 & 1246.097 & 0.123 & 1.130 & 0.339 & -1.081 & 198.645 & 0.020 & 1.020 & 0.714 & -0.337 \\
\hline 0.4 & 941.199 & 0.093 & 1.097 & 0.439 & -0.824 & 363.071 & 0.036 & 1.036 & 0.622 & -0.475 \\
\hline 0.5 & 672.217 & 0.066 & 1.068 & 0.534 & -0.627 & 583.459 & 0.057 & 1.059 & 0.530 & -0.636 \\
\hline 0.6 & 442.640 & 0.044 & 1.044 & 0.627 & -0.467 & 864.457 & 0.085 & 1.089 & 0.435 & -0.831 \\
\hline 0.7 & 256.276 & 0.025 & 1.026 & 0.718 & -0.331 & 1211.112 & 0.119 & 1.126 & 0.338 & -1.085 \\
\hline 0.8 & 117.283 & 0.012 & 1.012 & 0.809 & -0.212 & 1628.907 & 0.160 & 1.174 & 0.235 & -1.449 \\
\hline 0.9 & 30.203 & 0.003 & 1.003 & 0.903 & -0.102 & 2123.796 & 0.209 & 1.232 & 0.123 & -2.094 \\
\hline
\end{tabular}

Table-6: Optimized values of partial excess free energy of mixing, activity coefficients and activity of both the components present in In-Tl liquid alloys at 1323K.

\begin{tabular}{|c|r|r|r|r|r|r|r|r|r|r|}
\hline \multirow{2}{*}{$c_{I n}$} & \multicolumn{9}{|c|}{ In- component } & \multicolumn{4}{|c|}{ Tl-component } \\
\cline { 2 - 12 } & $\tilde{G}_{M, I n}^{X S}$ & $\ln \gamma_{I n}=\frac{\tilde{G}_{M, I n}^{X S}}{R T}$ & $\gamma_{I n}$ & $a_{I n}$ & $\ln a_{I n}$ & $\tilde{G}_{M, T l}^{X S}$ & $\ln \gamma_{T l}=\frac{\tilde{G}_{M, T l}^{X S}}{R T}$ & $\gamma_{T l}$ & $a_{T l}$ & $\ln a_{T l}$ \\
\hline 0.1 & 1671.564 & 0.152 & 1.164 & 0.116 & -2.151 & 17.899 & 0.002 & 1.002 & 0.901 & -0.104 \\
\hline 0.2 & 1356.951 & 0.123 & 1.131 & 0.226 & -1.486 & 73.567 & 0.007 & 1.007 & 0.805 & -0.216 \\
\hline 0.3 & 1067.779 & 0.097 & 1.102 & 0.331 & -1.107 & 170.134 & 0.015 & 1.016 & 0.711 & -0.341 \\
\hline 0.4 & 806.587 & 0.073 & 1.076 & 0.430 & -0.843 & 310.991 & 0.028 & 1.029 & 0.617 & -0.483 \\
\hline 0.5 & 576.129 & 0.052 & 1.054 & 0.527 & -0.641 & 499.816 & 0.045 & 1.046 & 0.523 & -0.648 \\
\hline 0.6 & 379.404 & 0.034 & 1.035 & 0.621 & -0.476 & 740.605 & 0.067 & 1.070 & 0.428 & -0.849 \\
\hline 0.7 & 219.684 & 0.020 & 1.020 & 0.714 & -0.337 & 1037.699 & 0.094 & 1.099 & 0.330 & -1.110 \\
\hline 0.8 & 100.546 & 0.009 & 1.009 & 0.807 & -0.214 & 1395.814 & 0.127 & 1.135 & 0.227 & -1.483 \\
\hline 0.9 & 25.896 & 0.002 & 1.002 & 0.902 & -0.103 & 1820.072 & 0.165 & 1.180 & 0.118 & -2.137 \\
\hline
\end{tabular}


The natural logarithms of optimized values of activities of both the components of In-Tl liquid alloys at different temperatures $\mathrm{T}=723 \mathrm{~K}, 1123 \mathrm{~K}, 1223 \mathrm{~K}$ and $1323 \mathrm{~K}$ in the entire concentration range are shown in Fig-7.

Again, the concentration fluctuations in long wave-length limit $\left\{S_{c c}(0)\right\}$ of In-Tl liquid alloys at different temperatures $\mathrm{T}=723 \mathrm{~K}, 1123 \mathrm{~K}, 1223 \mathrm{~K}$ and $1323 \mathrm{~K}$ in entire concentration range have been computed by using equation (11) with the help of the corresponding optimized values of the activities of both the components which are shown in Fig.-8.

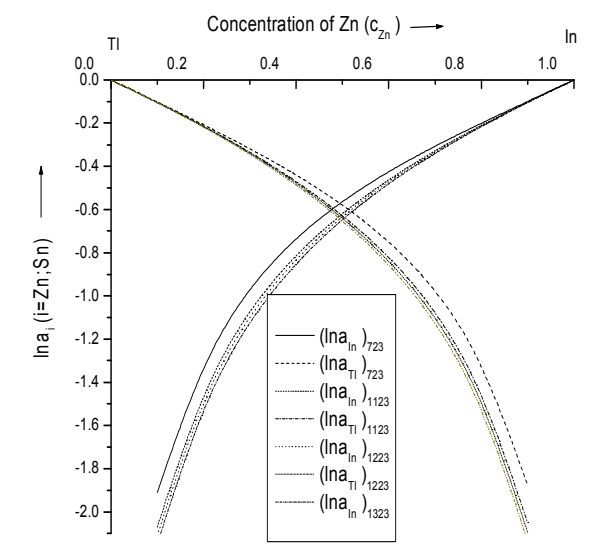

Fig-7:Graph for Optimized Ina versus $c_{\text {In }}$ of In-TI liquid alloys (i=In; TI) at different Temp.

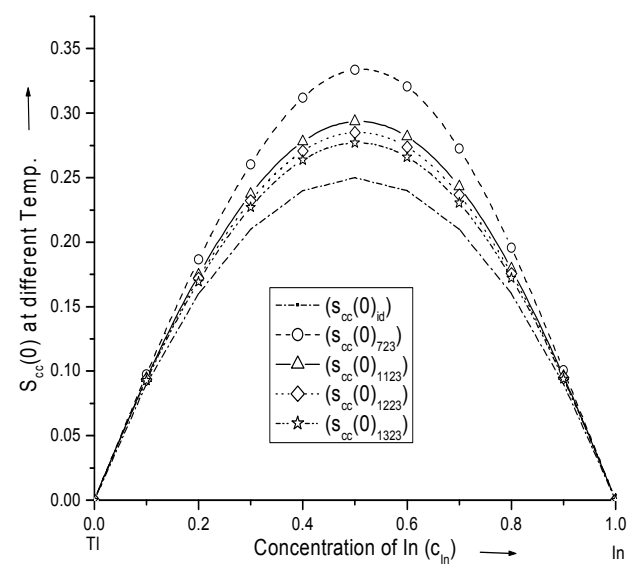

Fig-8:Graph for optimized values of $S_{c c}(0)$ versus $C_{\text {In }}$ of In-TI liquid alloys at different Temp.

From this result, It is concluded that the concentration fluctuations in long wavelength limit of In-Tl liquid alloys at the temperatures between $723 \mathrm{~K}$ and $1323 \mathrm{~K}$ decreases as the temperature increases and shift towards the ideal value of concentration fluctuations $\left(\mathrm{S}_{\mathrm{cc}}^{\mathrm{id}}(0)\right)$ at each concentration on increasing the temperature but remains greater than the ideal value of concentration fluctuations which indicates that the In-Tl liquid alloy has segregating nature in the entire concentration range but the segregating nature decreases as the temperature increases.

From the relation for excess stability function $\left(E^{X S}\right)=\left(\frac{\partial^{2} G_{M}^{X S}}{\partial C^{2}}\right)=R T\left[\frac{1}{S_{C C}(0)}-\right.$ $\left.\frac{1}{S_{C C}^{i d}(0)}\right][23]$, the excess stability function at the temperature $\mathrm{T}=723 \mathrm{~K}, 1123 \mathrm{~K}, 1223 \mathrm{~K}$ and $1323 \mathrm{~K}$ in the entire concentration range have been calculated from optimized data which are shown in Fig-9 and they give the idea to predict stability of In-Tl liquid alloys at different temperatures.

This result suggests that the excess stability function of In-Tl liquid alloy becomes less and less negative as the temperature increases more and more which indicates that the stability of In-Tl liquid alloy increases as the temperature increases i.e. the bond strength between unlike

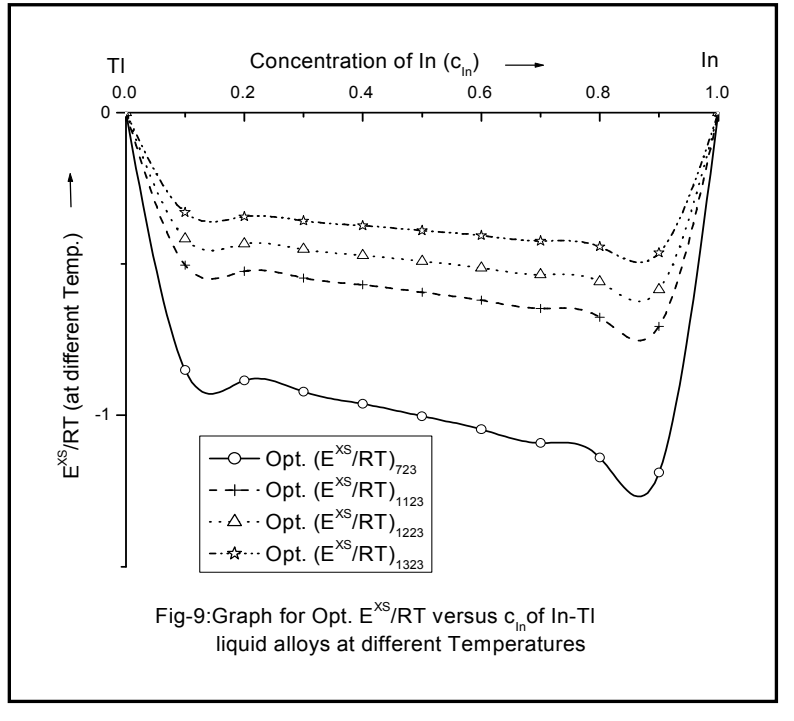
atoms of the alloy increases as the temperature increases. 
Again, the Diffusion coefficients $\left(\frac{D_{m}}{D_{i d}}\right)$ of In-Tl liquid alloy at different temperatures in the entire concentration range can also be computed by using the optimized data from the relation $\frac{D_{m}}{D_{i d}}=\frac{S_{c c}^{i d}(0)}{S_{c c}(0)}[23]$, which are shown in Fig-10.

This result reveals that the diffusion coefficient for In-Tl liquid alloys increases as the temperature increases in the entire concentration range.

In order to determine the extreme condition of segregation, i.e. phase separation, we can use the knowledge of Warren-Cowley short

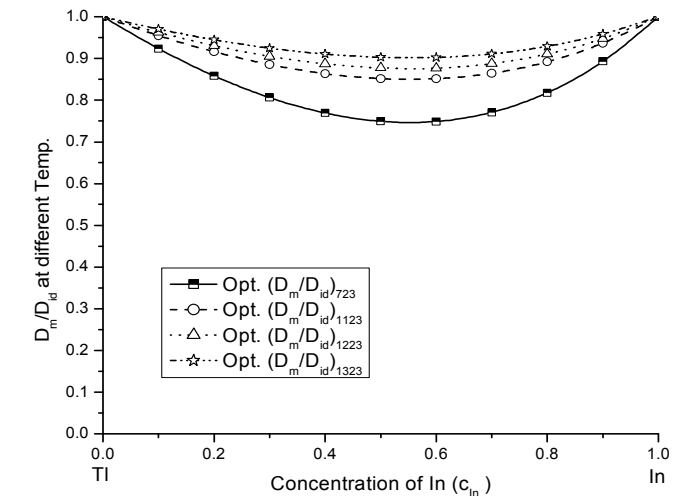

Fig-10:Graph for Opt. $D_{m} / D_{\text {id }}$ versus $c_{\text {In }}$ of In-TI liquid alloys at different Temp.

range order parameter (SRO), $\alpha_{1}$, for the first neighbour shell $(l=1)$ which is directly related to $S_{c c}(0)$ and represented by the relation [23]

$$
\alpha_{1}=\frac{S^{*}-1}{S^{*}(Z-1)+1}
$$

where $\mathrm{Z}$ is the co-ordination number and $S^{*}=\frac{S_{c c}(0)}{S_{c c}^{i d}(0)}$

The optimized values of $\alpha_{1}$ (computed from the above relation on taking $Z=10$ ) of InTl liquid alloys at different temperature is shown in Fig-11, which exhibits the temperature dependence of $\operatorname{SRO}\left(\alpha_{1}\right)$ in the entire concentration range.

Our result reveals that the values of SRO $\left(\alpha_{1}\right)$ are positive at all the temperatures such that the value of $\alpha_{1}$ increases on decreasing the temperature. Its value is far lower than the required value for phase separation, i.e. $\alpha_{\max }=+1$, even at the lowest temperature under consideration. At all the temperatures under consideration,

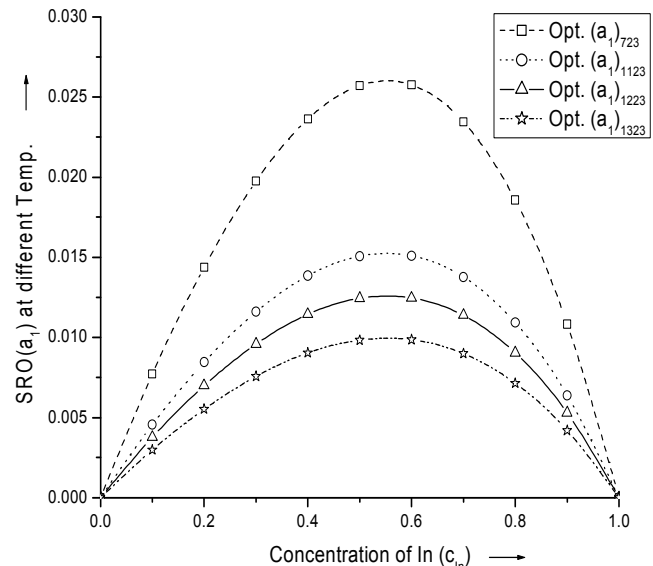

Fig-11:Graph for Optimized $\mathrm{SRO}\left(\mathrm{a}_{1}\right)$ versus $\mathrm{c}_{\mathrm{In}}$ of $\mathrm{In}$-TI liquid alloys at different Temp. the magnitude of $\alpha_{1}$ is though positive but much less than unity which indicates that the In-Tl binary liquid alloy is weak homo-coordinated alloy.

\section{Conclusions}

The following conclusions may be drawn from the study of this theoretical investigation in In-Tl liquid alloys:

- The size ratio $(\Omega)$ plays vital role in determining the mixing properties of the In-Tl liquid alloys at a specified temperature but its effect in the values of other thermodynamic and structural properties of the alloy due to temperature change is only negligible and hence it is taken as constant at all above temperatures.

- The order energy parameter (W) plays important role in determining the mixing properties of the In-Tl liquid alloys which has a fixed value at a particular temperature and it is temperature dependent. The values of $\mathrm{W}$ between temperature range $723 \mathrm{~K}$ and $1323 \mathrm{~K}$ in $\mathrm{In}-\mathrm{Tl}$ liquid alloys are + ve and its value decreases as the temperature increases which indicates that the segregating nature of the alloy decreases as the temperature increases. 
- The values of concentration fluctuations in long wavelength limit between temperature range $723 \mathrm{~K}$ and $1323 \mathrm{~K}$ in In-Tl liquid alloys are always greater than the ideal value of concentration fluctuations at each concentration so that this alloy is of segregating nature in this range of temperature.

- The concentration fluctuations in long wavelength limit of In-Tl liquid alloy decreases as the temperature increases at each concentration and shifts towards the ideal value of concentration fluctuation as the temperature increases which indicates that the segregating nature of the alloy decreases as the temperature increases.

- The Free energy of mixing $\left(\mathrm{G}_{\mathrm{M}}\right)$, Entropy of mixing $\left(\mathrm{S}_{\mathrm{M}}\right)$, Heat of mixing $\left(\mathrm{H}_{\mathrm{M}}\right)$ and the concentration fluctuations $\left(S_{c c}(0)\right)$ in long wavelength limit of In-Tl liquid alloys are symmetrical at the equiatomic composition of its constituents (i.e. $\mathrm{c}=0.5$ ) so that it is symmetric alloy.

- The excess free energy of mixing in In-Tl liquid alloy decreases as the temperature of the alloy increases which indicates that the bonding strength between unlike atoms present in the alloys increases as temperature increases.

- The excess stability function of In-Tl liquid alloy becomes less and less negative as the temperature increases more and more which indicates that the stability of In-Tl liquid alloy increases as the temperature increases.

- The diffusion coefficient for In-Tl liquid alloys in the entire concentration range increases as the temperature increases.

- The values of SRO $\left(\alpha_{1}\right)$ are positive at all the temperatures under consideration such that the value of $\alpha_{1}$ increases on decreasing the temperature which is far lower than the required value for phase separation, i.e. $\alpha_{\max }=+1$, even at the lowest temperature under consideration so that the In-Tl binary liquid alloy is weak homo-coordinated alloy.

\section{References}

[1] I. Koirala, B. P. Singh, I. S. Jha, Theoretical assessment on segregating nature of liquid In-T1 alloys, J. Non. Cryst. Solids 398-399 (2014) 26-31. doi.org/10.1016/j.jnoncrysol.2014.04.018.

[2] I. Koirala, I. S. Jha, B. P. Singh, D. Adhikari, The thermodynamic, transport and surface properties in In-Pb liquid alloys, Phys. B 423(2013) 49-53.doi.org/10.1016/j.physb.2013.04.051.

[3] I. Koirala, B. P. Singh, I. S. Jha, Correlation of bulk and surface properties in Bi-Sn and Bi-In liquid alloys, Adv. Mater. Lett. 6 (2015) 646-652.

[4] Yu. Plevachuk, V. Didoukh, B. Sokolovskii, The miscibility gap region and liquid-liquid equilibrium in immiscible In-Tl-Te alloys, J. Alloys and Compounds 274 (1998) 206-208. doi.org/10.1016/S0925-8388(98)00554-4.

[5] A. B. Bhatia, R. N. Singh, Thermodynamic properties of compound forming aolten Alloys in a weak interaction approximation, Phys. Chem. Liq. 11 (1982) 343-351. doi.org/10.1080/00319108208080755.

[6] B. P. Singh, R. P. Koirala, I. S. Jha, D. Adhikari, Thermodynamic, structural and surface properties of Sn- Zn melt at 750K, Appl. Phys. A-Material Sci. Process. 120 (2015) 1347-1356. doi.org/ 10.1007/s00339-015-9316-8.

[7] B. P. Singh, I. Koirala, I. S. Jha, D. Adhikari, The segregating nature of $\mathrm{Cd}-\mathrm{Pb}$ liquid binary alloys, Phys. Chem. Liq. 52 (2014) 457-470. doi.org/10.1080/00319104.2013.871668.

[8] D. Adhikari, I. S. Jha, B. P. Singh, Structural asymmetry in liquid Fe-Si alloys, Philos. Mag. 90 (2010) 2687-2694. doi.org/10.1080/14786431003745302.

[9] E. O. Ilo-Okeke, B. C. Anusionwu, O. Popoola, Thermodynamic evaluation of viscosity in In-Zn and Sn-Zn liquid alloys, Phys. Chem. Liq. 43 (2005) 333-342. doi.org/10.1080/00319100500087964. 
[10] J. A. Alonso, N. H. March, Concentration fluctuations in simple metallic liquid alloys, Phys. B+C 114 (1982) $67-70$.

[11] L. C. Prasad and R. N. Singh, A Quasi-lattice model for the thermodynamic properties of Au-Zn liquid alloys, Phys. Chem. Liq. 22 (1989) 37-41.

[12] O. Akinlade, R. N. Singh, F. Sommer, Thermodynamics of liquid Al-Fe alloys, J. Alloys Compd. 299 (2000) 163-168. doi.org/10.1016/S0925-8388(99)00682-9.

[13] M. Hoch, Application of the complex model to liquid metal-salt systems, Calphad 9 (1985)59-70. doi.org/10.1016/0364-5916(85)90031-8.

[14] O. E. Awe, I. Akinwale, J. Imeh, J. Otu, Calculation of experimental concentration-concentration fluctuations of liquid binary alloys using experimental free energy of mixing and experimental activities, Phys. Chem. Liq. 48 (2010) 243-256. doi.org/10.1080/00319100902822760.

[15] P. J. Flory, Thermodynamics of high polymer solutions, J. Chem. Phys. 1 .(1942) 51. doi.org/10.1063/1.1723621.

[16] R. P. Koirala, J. Kumar, B. P. Singh, D. Adhikari, Bulk and surface properties of Co-Fe and Fe-Pd liquid alloys, J. Non. Cryst. Solids 394-395 (2014) 9-15. doi.org/10.1016/j.jnoncrysol.2014.04.001.

[17] R. P. Koirala, B. P. Singh, I. S. Jha, D. Adhikari, Thermodynamic, Structural and surface properties of liquid Cd-Zn Alloys, J. Mol. Liq. 179 (2013) 60-66. doi.org/10.1016/j.molliq.2012.12.008.

[18] R. P. Koirala, B. P. Singh, I. S. Jha, D. Adhikari, Thermodynamic and structural behavior of liquid AlGa alloys, Adv. Mater. Lett. 4 (2013) 283-287.doi.org/10.5185/amlett.2012.8412.

[19] S. K. Yadav, L. N. Jha, I. S. Jha, B. P. Singh, R. P. Koirala, D. Adhikari, Prediction of thermodynamic and surface properties of $\mathrm{Pb}-\mathrm{Hg}$ liquid alloys at different temperatures, Philos. Mag. 96 (2016) 19091925. doi.org/10.1080/14786435.2016.1181281.

[20] W. H. Young, Structural and thermodynamic properties of NFE liquid metals and binary alloys, Reports Prog. Phys. 55 (1992) 1769-1853. doi.org/10.1088/0034-4885/55/10/003.

[21] Y. J. Lv, M. Chen, Thermophysical Properties of Undercooled Alloys: An Overview of the Molecular Simulation Approaches, Int. J. Mol. Sci. 12 (2011) 278-316.doi.org/10.3390/ijms12010278.

[22] G.K. Shrestha, B. K. Singh, I.S. Jha, B.P. Singh, D. Adhikari, Optimization method for the study of the properties of Al-Sn binary liquid alloys, Physica B 514(2017) 1-7. doi.org/10.1016/i.physb.2017.03.005.

[23] R. N. Singh, F. Sommer, Segregation and immiscibility in liquid binary alloys, Reports Prog. Phys. 60 (1997) 57-150. doi.org/10.1088/0034-4885/60/1/003.

[24] E. A. Guggenheim, Mixtures. Oxford University Press, London, 1952.

[25] A. B. Bhatia, D. E. Thornton, Structural aspects of the electrical resistivity of binary alloys, Phys. Rev. B 2 (1970) 3004-3012. doi.org/10.1103/PhysRevB.2.3004.

[26] R. N. Singh, Short-range order and concentration fluctuations in binary molten alloys, Can. J. Phys. 65 (1987) 309-325. doi.org/10.1139/p87-038

[27] M. Shimoji, Liquid Metals. Academic Press, 1977.

[28] R. Hultgren, P. D. Desai, D. T. Hawkins, M. Gleiser K. K. Kelley, Selected Values of Thermodynamic Properties of Binary Alloys. Metal Park, ASM International, OHIO, 1973. 